\title{
The Effect of Supply and Outdoor Air Temperature on The Enthalpy and Temperature Exchange Efficiency of a Paper Heat Exchanger
}

\author{
Teoh Zhi Heng ${ }^{1}$, Abudulkareem Sh. Mahdi Al-Obaidi ${ }^{1, *}$, Chin Wai Meng ${ }^{2}$, and Kenny \\ James Ling Neng Hui ${ }^{2}$ \\ ${ }^{1}$ School of Computer Science and Engineering, Taylor's University Lakeside Campus, 47500 Subang \\ Jaya, Malaysia \\ ${ }^{2}$ Technology Research Department, Daikin Research \& Development Malaysia Sdn. Bhd., 47000 \\ Sungai Buloh, Malaysia
}

\begin{abstract}
Heat Recovery Ventilator (VHR) is widely used nowadays as it is capable to maintain high Indoor Air Quality (IAQ) while minimizing the energy loss of indoor air through air-to-air heat exchanger principle. The main component that enables VHR to perform air-to-air heat exchange is known as Paper Heat Exchanger (PP-HEX). Hence, the objective of this research is to study and analyse the performance of a PP-HEX under different return and outdoor air temperatures as well as their effect on both enthalpy and temperature exchange efficiency. Moreover, some numerical models of VHR have been developed to optimize some complex cases and the numerical models are meant to reduce the physical experiments to analyze or improve complex cases in the future. To the best of the authors knowledge, there is no experimental data available from any sources to validate the numerical models. To address this issue, two different supplies of PP-HEX are tested with an actual VHR, and both PP-HEXs will be referred to as PP-HEX-A and PP-HEX-B due to confidentiality. Furthermore, the testing is conducted in a temperature-controlled testing laboratory and the testing conditions are set according to the ISO standard. The preliminary testing results show that the temperature exchange efficiency and enthalpy exchange efficiency of the PP-HEXs have the same trends while the outdoor air temperature is fixed and varying the temperature of indoor air. In contrary, the temperature exchange efficiency and enthalpy exchange efficiency of the PP-HEXs have the same trends while the indoor air temperature is fixed and varying the temperature of outdoor air as well. With the default voltage supplies (240V) to VHR and the setup conditions (according to the ISO Standard) of return air to be $27^{\circ} \mathrm{C}$ and outdoor air to be $35^{\circ} \mathrm{C}$, the testing results show that PP-HEX-A has a temperature exchange efficiency and enthalpy exchange efficiency with a range of $(37.97-40.28)$ $\%$ and $(30.77-57.81) \%$ respectively. While PP-HEX-B has a temperature exchange efficiency and enthalpy exchange efficiency with a range of (35.29 $-42.5) \%$ and $(39.6-55.93) \%$ respectively.
\end{abstract}

\footnotetext{
* Corresponding author: abdulkareem.mahdi@taylors.edu.my
} 


\section{Introduction}

The Heating, Ventilation and Air-Conditioning (HVAC) system is an integrated system that provides environmental comfort to the human activity spaces and maintains the high level of Indoor Air Quality (IAQ). As part of HVAC, the ventilation system plays an important role as it can affect the human's health and comfort. In an optimistic case, an enclosed space for instance, like an office that ran out of fresh air and the people in the space would feel stuffy and uncomfortable due to lacking fresh air. In the worst case, the enclosed space could be contaminated with toxins or viruses and affect human health or even cause people to fall sick. Nowadays, the ventilation system is improvised to provide a better IAQ by replenishing fresh air and removing the carbon dioxide and contaminated air (odours, bacteria, dust etc.) [1]. According to studies, $(80-90) \%$ of human living times are spent indoors [2]. Hence, IAQ plays an important role which would tremendously affect human's health.

In this current era, one of the main focuses of the industry is on the energy recovery within buildings [3]. It is rather important to have proper thermal insulation and energy recovery systems [4, 5]. To this, various implementations and innovations through technologies had been developed across time, in which the current HVAC system is one of the dominating systems in the market due to its high feasibility on energy recovery for buildings [6]. Heat Recovery Ventilator (VHR), being the most well-known mechanism for energy recovery, became a favourable solution across the globe due to its suitability for each climate [7]. Number of studies have shown that VHR is rather effective in recovering energy [8], being in cool climates or adopting high-rise buildings or buildings with large compounds such as universities $[9,10]$.

VHR is commonly used in enclosed areas such as corporate buildings and residential edifices with the aim to conserve energy from heating and cooling the space. Besides, it's also used to enhance the IAQ by exchanging indoor and outdoor air which purifies it [11]. Some numerical models of VHR such as the CFD model have been developed for the purpose of optimization in some complex cases [12]. Unfortunately, there was a lack of experimental data to validate the developed numerical models due to limitations of resources available. Moreover, the experimental data were limited also due to the presence of data which were only feasible for some certain climates, which the boundary conditions could not be applied on [13]. Resources available on open sources in the meantime are mostly theoretical studies instead of experimental studies for both tropical and winter climates [14].

Hence, the objective of this research is to study and analyze the performance of a PP-HEX under different return and outdoor air temperatures as well as their effect on both enthalpy and temperature exchange efficiency. The results of the efficiencies help to determine the characteristics of the PP-HEX and to validate the results of numerical analysis.

\section{Methodology}

This quantitative research involved the experimental testing of two PP-HEXs provided by different manufacturers with an actual VHR. Due to confidentiality, the properties and manufacture sources of the PP-HEXs should not be disclosed, hence, both PP-HEXs will be referred as PP-HEX-A and PP-HEX-B respectively. The VHR will be placed in a laboratory with the features of controlling the temperature to go through four sets of testing scenarios for each PP-HEX. On top of that, voltage supplies for the VHR will be controlled as well. The voltage for the VHR in first and second testing scenarios will be set at $240 \mathrm{~V}$, where the voltage for VHR in third and fourth testing scenarios will be set at $120 \mathrm{~V}$. 
Controlling the voltage supply serves a purpose of controlling the air velocity this is because the PP-HEX is used in certain range of air velocity in different product variant. All these scenarios are set according to the ISO standard which is proposed by the industrial supervisor. Figure 1 shows the schematic diagram of the testing set-up.

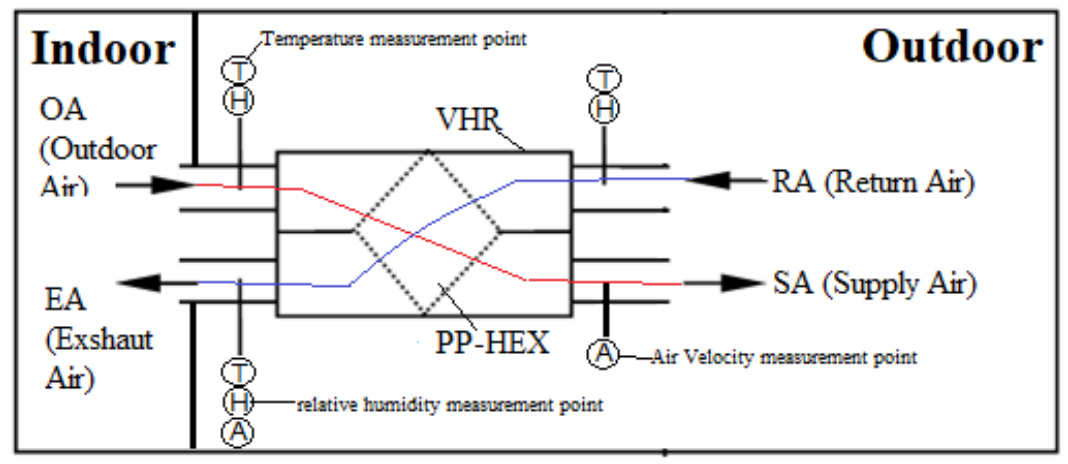

Fig. 1. Schematic Diagram of Experiment Set-up.

\subsection{Key experimental elements}

In this research, experiments are conducted, and they are carried out in a laboratory with features of controlling the temperature. The aim of the experiment is to analyze the effect of supply and outdoor air temperature on the enthalpy and temperature exchange efficiency of both PP-HEX-A and PP-HEX-B. On top of that, PP-HEX-A and PP-HEX-B are used to validate the experimental results and both PP-HEXs were manufactured with similar materials. Hence the performance of both PP-HEXs will be similar regardless of the Temperature Exchange Efficiency and Enthalpy Exchange Efficiency. Furthermore, the key parameters that affect the efficiencies during the experiment are as follow:

- The relative humidity of indoor and outdoor air

- The temperature of indoor and outdoor air

- The insulation of the testing laboratory

\subsection{First testing scenario}

In the first testing scenario, it is advised that the temperature of outdoor air (OA) is to be $35^{\circ} \mathrm{C}$, return air (RA) is to be $27^{\circ} \mathrm{C}$ as these are the preliminary ISO standard of the testing conditions. In this testing scenario, it is meant to determine the effect on the temperature exchange efficiency and enthalpy exchange efficiency while OA has a fixed temperature and varying the temperature of RA. Furthermore, VHR consists of two motor fan blowers and located at supply air (SA) and exhaust air (EA) side. Hence, a voltage regulator will be used to control the voltage supplies of the SA and EA side to input the supply voltage to $240 \mathrm{~V}$. In the first testing scenario, PP-HEX-A will be tested with a constant OA temperature of $35^{\circ} \mathrm{C}$ and varying the RA temperature to $21^{\circ} \mathrm{C}, 23^{\circ} \mathrm{C}, 25^{\circ} \mathrm{C}, 27^{\circ} \mathrm{C}, 29^{\circ} \mathrm{C}$. The temperature and relative humidity of RA, EA and SA will be recorded by anemometer. The analysis of temperature exchange efficiency and enthalpy exchange efficiency can be conducted with the raw data recorded by an anemometer. After the first testing scenario for PP-HEX-A is done, the PP-HEX-A will be replaced with PP-HEX-B to repeat the procedure from the first testing scenario and analyze the experimental results. 


\subsection{Second testing scenario}

The second testing scenario is more likely to be a vice versa of the first testing scenario. In this testing scenario, it is meant to determine the effect on the temperature exchange efficiency and enthalpy exchange efficiency while RA has a fixed temperature and varying the temperature of OA. The second testing scenario will be tested according to the ISO standard of testing condition as well. Hence, the temperature of RA will be fixed at $27^{\circ} \mathrm{C}$ while the temperature of $\mathrm{OA}$ will be varying to $29^{\circ} \mathrm{C}, 31^{\circ} \mathrm{C}, 33^{\circ} \mathrm{C}, 35^{\circ} \mathrm{C}, 37^{\circ} \mathrm{C}$. On top of that, the voltage supplies of SA and EA will remain the same as in the first testing scenario. The temperature and relative humidity of RA, EA and SA will be recorded by anemometer. The analysis of temperature exchange efficiency and enthalpy exchange efficiency can be conducted with the raw data recorded by an anemometer. After the first testing scenario for PP-HEX-A is done, the PP-HEX-A will be replaced with PP-HEX-B to repeat the procedure from the first testing scenario and analyze the experimental results.

\subsection{Third testing scenario}

The third testing scenario has the same testing procedure as the first testing scenario. However, the voltage supplies to SA and EA are required to change to $120 \mathrm{~V}$ in this testing scenario. The temperature and relative humidity of RA, EA and SA will be recorded by anemometer. The analysis of temperature exchange efficiency and enthalpy exchange efficiency can be conducted with the raw data recorded by an anemometer. After the first testing scenario for PP-HEX-A is done, the PP-HEX-A will be replaced with PP-HEX-B to repeat the procedure from the first testing scenario and analyze the experimental results.

\subsection{Fourth testing scenario}

The fourth testing scenario has the same testing procedure as the second testing scenario. However, the voltage supplies to SA and EA are required to change to $120 \mathrm{~V}$ in this testing scenario. The temperature and relative humidity of RA, EA and SA will be recorded by anemometer. The analysis of temperature exchange efficiency and enthalpy exchange efficiency can be conducted with the raw data recorded by an anemometer. After the first testing scenario for PP-HEX-A is done, the PP-HEX-A will be replaced with PP-HEX-B to repeat the procedure from the first testing scenario and analyze the experimental results.

\subsection{Analysis of temperature exchange efficiency}

According to the American Society of Heating, Refrigerating and Air-Conditioning Engineers (ASHRAE) standard, the temperature of OA, SA and RA at different conditions, temperature exchange efficiency can be determined by Eq. (1), which shows the general equation of temperature exchange efficiency for the calculation [15]:

$$
\text { Temperature Exchange Efficiency, } \eta_{T}=\frac{T_{\text {Return Air }}-T_{\text {Supply Air }}}{T_{\text {Indoor Air }}-T_{\text {Supply Air }}} \times 100 \%
$$

\subsection{Analysis of enthalpy exchange efficiency}

The raw data of the testing are mainly recorded as the temperature and relative humidity. Hence, the enthalpy is required to be determined by using a psychrometric chart. However, there is a psychrometric chart software available from the industrial side where the enthalpy 
will be displayed by inputting the values of temperature and relative humidity. Figure 2 shows the psychrometric chart software that is used to determine the enthalpy.

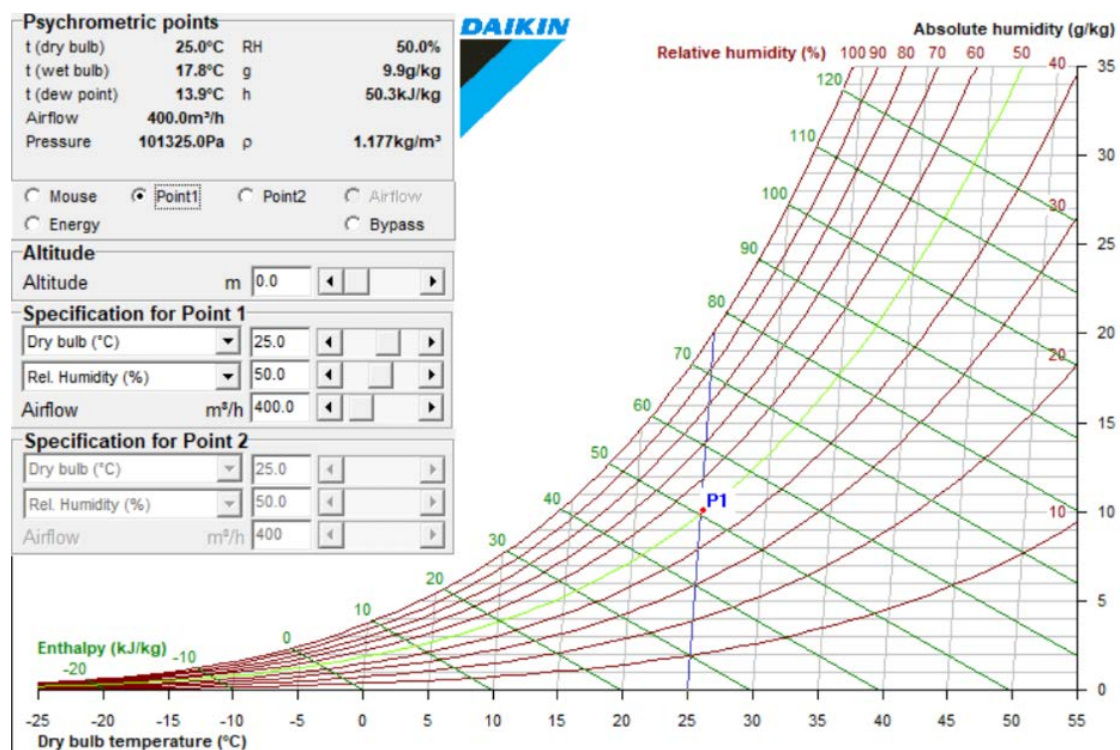

Fig. 2. Psychrometric Chart Software.

According to the ASHRAE standard [15], the enthalpy of OA, SA and RA at different conditions, enthalpy exchange efficiency can be determined using Eq. (2), which shows the general equation of enthalpy exchange efficiency for the calculation:

Enthalpy Exchange Efficiency, $\eta_{h}=\frac{h_{\text {Return Air }}-h_{\text {Supply Air }}}{h_{\text {Indoor Air }}-h_{\text {Supply Air }}} \times 100 \%$

\section{Results and Discussion}

\subsection{First testing scenario}

The raw data, enthalpy, temperature exchange efficiency and enthalpy exchange efficiency of the first testing scenario of both PP-HEXs are tabulated as shown in Tables 1, 2 and 3 respectively.

Table 1. Raw data of first testing scenario.

\begin{tabular}{|c|c|c|c|c|c|c|c|c|c|c|c|}
\hline \multicolumn{4}{|c|}{ PP-HEX-A } & \multicolumn{6}{c|}{ PP-HEX-B } \\
\hline \multicolumn{2}{|c|}{ Temperature $\left({ }^{\circ} \mathbf{C}\right)$} & \multicolumn{3}{|c|}{$\begin{array}{c}\text { Relative Humidity } \\
(\%)\end{array}$} & \multicolumn{2}{c|}{ Temperature $\left({ }^{\circ} \mathbf{C}\right)$} & \multicolumn{3}{|c|}{$\begin{array}{c}\text { Relative Humidity } \\
(\%)\end{array}$} \\
\hline RA & SA & OA & RA & SA & OA & RA & SA & OA & RA & SA & OA \\
\hline 23.1 & 29.4 & 35.1 & 73.1 & 49 & 38 & 24.2 & 31.1 & 35.1 & 58.6 & 42.5 & 38.5 \\
\hline 25 & 31 & 35 & 73.3 & 50.5 & 39.8 & 25.3 & 31.5 & 35 & 59.2 & 43.5 & 38.7 \\
\hline 26.9 & 31.8 & 34.8 & 75.8 & 51.8 & 40.8 & 26.5 & 32 & 35 & 57.2 & 42.2 & 36.7 \\
\hline 29 & 32.9 & 34.9 & 73.3 & 50.9 & 42.5 & 28.8 & 33.1 & 35.1 & 63.4 & 45 & 38.2 \\
\hline
\end{tabular}


Table 2. Enthalpy of the air under different conditions.

\begin{tabular}{|c|c|c|c|c|c|c|}
\hline \multirow[b]{2}{*}{$\begin{array}{l}\text { Temperature } \\
\text { of RA }\left({ }^{\circ} \mathbf{C}\right)\end{array}$} & \multicolumn{3}{|c|}{ PP-HEX-A } & \multicolumn{3}{|c|}{ PP-HEX-B } \\
\hline & $\begin{array}{c}\text { RA, } \\
\text { Enthalpy } \\
\text { (kJ/kg) }\end{array}$ & $\begin{array}{c}\text { SA, } \\
\text { Enthalpy } \\
(\mathbf{k J} / \mathbf{k g})\end{array}$ & $\begin{array}{c}\text { OA, } \\
\text { Enthalpy } \\
(\mathbf{k J} / \mathbf{k g})\end{array}$ & $\begin{array}{c}\text { RA, } \\
\text { Enthalpy } \\
\text { (kJ/kg) }\end{array}$ & $\begin{array}{c}\text { SA, } \\
\text { Enthalpy } \\
(\mathbf{k J} / \mathbf{k g})\end{array}$ & $\begin{array}{c}\text { OA, } \\
\text { Enthalpy } \\
(\mathbf{k J} / \mathbf{k g})\end{array}$ \\
\hline 23 & 56.2 & 61.7 & 69.9 & 52.5 & 62 & 70.4 \\
\hline 25 & 62.3 & 67.6 & 71.3 & 55.9 & 63.9 & 70.2 \\
\hline 27 & 70.3 & 71.2 & 71.6 & 58.3 & 64.4 & 68.4 \\
\hline 29 & 76.6 & 74.2 & 73.4 & 69.3 & 69.9 & 70.1 \\
\hline
\end{tabular}

Table 3. Temperature Exchange Efficiency and Enthalpy Exchange Efficiency.

\begin{tabular}{|c|c|c|c|c|}
\hline \multirow{2}{*}{$\begin{array}{c}\text { Temperature } \\
\text { of RA }\left({ }^{\circ} \mathbf{C}\right)\end{array}$} & $\begin{array}{c}\text { Pempera } \\
\text { Exchange } \\
\text { Efficiency } \\
(\boldsymbol{\%})\end{array}$ & $\begin{array}{c}\text { Enthalpy } \\
\text { Exchange } \\
\text { Efficiency } \\
(\boldsymbol{\%})\end{array}$ & $\begin{array}{c}\text { Tempera } \\
\text { Exchange } \\
\text { Efficiency } \\
(\boldsymbol{\%})\end{array}$ & $\begin{array}{c}\text { Enthalpy } \\
\text { Exchange } \\
\text { Efficiency } \\
(\boldsymbol{\%})\end{array}$ \\
\hline 23 & 47.50 & 59.85 & 36.70 & 46.93 \\
\hline 25 & 40.00 & 41.11 & 36.08 & 44.06 \\
\hline 27 & 37.97 & 30.77 & 35.29 & 39.60 \\
\hline 29 & 33.90 & 25.00 & 31.75 & 25.00 \\
\hline
\end{tabular}

Figure 3 shows the effect of the temperature exchange efficiency and enthalpy exchange efficiency as a function of the temperature of RA of both PP-HEXs for the first testing scenario. Based on Figure 3, the temperature exchange efficiency and enthalpy exchange efficiency of both PP-HEXs have the similar trends of inversely proportional, which means that the efficiencies drop as the temperature of RA increases. Note that the temperature of OA was fixed, and the temperature of RA is varying, therefore it could be also understood that the smaller the difference of the temperature between the OA and RA, the lower the temperature exchange efficiency and enthalpy exchange efficiency. In another words, the efficiency of the VHR is affected by the temperature difference between the OA and RA where this is also supported by a findings which concluded that the temperature difference [16], air leakage and heat generated by the motor fan blowers [17] are the main parameters that affect the heat recovery system or the VHR. Moreover, it could be seen that the temperature exchange efficiency does not fluctuate much as compared with enthalpy exchange efficiency.

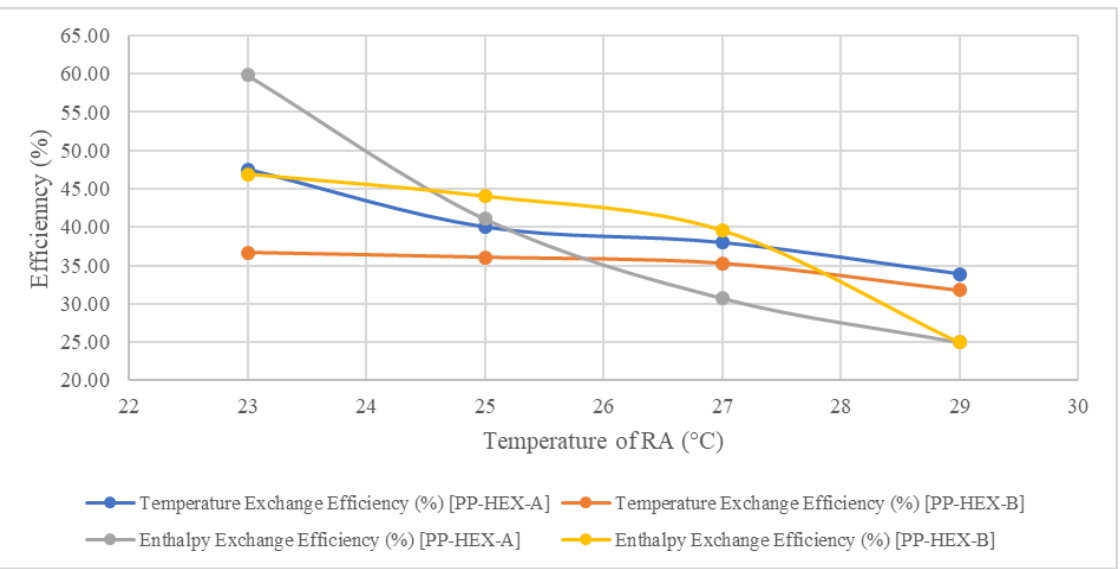

Fig. 3. Efficiency vs Temperature of RA. 


\subsection{Second testing scenario}

The raw data, enthalpy, temperature exchange efficiency and enthalpy exchange efficiency of the second testing scenario of both PP-HEXs are tabulated as shown in Tables 4, 5 and 6 respectively.

Table 4. Raw data of second testing scenario.

\begin{tabular}{|c|c|c|c|c|c|c|c|c|c|c|c|}
\hline \multicolumn{6}{|c|}{ PP-HEX-A } & \multicolumn{6}{|c|}{ PP-HEX-B } \\
\hline \multicolumn{3}{|c|}{$\begin{array}{c}\text { Temperature } \\
\left({ }^{\circ} \mathrm{C}\right)\end{array}$} & \multicolumn{3}{|c|}{$\begin{array}{c}\text { Relative } \\
\text { Humidity }(\%) \\
\end{array}$} & \multicolumn{3}{|c|}{$\begin{array}{c}\text { Temperature } \\
\left({ }^{\circ} \mathbf{C}\right)\end{array}$} & \multicolumn{3}{|c|}{$\begin{array}{c}\text { Relative } \\
\text { Humidity }(\%) \\
\end{array}$} \\
\hline RA & SA & $\mathbf{O A}$ & $\mathbf{R A}$ & $\mathbf{S A}$ & $\mathbf{O A}$ & RA & SA & $\mathbf{O A}$ & RA & SA & OA \\
\hline 26.9 & 28.8 & 28.9 & 63 & 56.5 & 58 & 26.9 & 29.2 & 29.3 & 63.8 & 55.6 & 57.5 \\
\hline 27 & 29.8 & 30 & 66 & 51.6 & 50.5 & 27.4 & 30.2 & 31.1 & 64.3 & 51.5 & 48.6 \\
\hline 27.1 & 30.7 & 32.5 & 64 & 48.1 & 42.9 & 27.2 & 31 & 32.8 & 64.7 & 48.2 & 42.5 \\
\hline 27 & 31.3 & 34.2 & 66 & 49.2 & 42.6 & 27.1 & 31.7 & 35.1 & 66 & 47.8 & 39.3 \\
\hline 27.2 & 32.1 & 36.6 & 64.4 & 46.9 & 37.8 & 26.9 & 32.1 & 37.2 & 66.8 & 49 & 39.1 \\
\hline
\end{tabular}

Table 5. Enthalpy of the air under different conditions.

\begin{tabular}{|c|c|c|c|c|c|c|}
\hline \multirow{2}{*}{$\begin{array}{c}\text { Temperature } \\
\text { of OA }\left({ }^{\circ} \mathbf{C}\right)\end{array}$} & \begin{tabular}{c}
$|c|$ \\
\cline { 2 - 7 } \\
\cline { 2 - 7 } \\
Enthalpy \\
$(\mathbf{k J} / \mathbf{k g})$
\end{tabular} & $\begin{array}{c}\text { SA, } \\
\text { Enthalpy } \\
(\mathbf{k J} / \mathbf{k g})\end{array}$ & $\begin{array}{c}\text { OA, } \\
\text { Enthalpy } \\
(\mathbf{k J} / \mathbf{k g})\end{array}$ & $\begin{array}{c}\text { RA, } \\
\text { Enthalpy } \\
(\mathbf{k J} / \mathbf{k g})\end{array}$ & $\begin{array}{c}\text { SA, } \\
\text { Enthalpy } \\
(\mathbf{k J} / \mathbf{k g})\end{array}$ & $\begin{array}{c}\text { OA, } \\
\text { Enthalpy } \\
(\mathbf{k J} / \mathbf{k g})\end{array}$ \\
\hline 29 & 62.8 & 64.8 & 66.1 & 63.3 & 65.5 & 67.1 \\
\hline 31 & 64.9 & 64.7 & 64.5 & 65.2 & 65.9 & 66.5 \\
\hline 33 & 63.7 & 65 & 66.4 & 64.8 & 65.9 & 67 \\
\hline 35 & 64.9 & 67.6 & 71.3 & 65.2 & 67.8 & 71.1 \\
\hline 37 & 64.6 & 68.3 & 74.3 & 65 & 70 & 77.5 \\
\hline
\end{tabular}

Table 6. Temperature Exchange Efficiency and Enthalpy Exchange Efficiency.

\begin{tabular}{|c|c|c|c|c|}
\hline \multirow{2}{*}{$\begin{array}{c}\text { Temperature } \\
\text { of OA }\left({ }^{\circ} \mathbf{C}\right)\end{array}$} & $\begin{array}{c}\text { Tempera } \\
\text { Exchange } \\
\text { Efficiency } \\
(\boldsymbol{\%})\end{array}$ & $\begin{array}{c}\text { Enthalpy } \\
\text { Exchange } \\
\text { Efficiency } \\
(\boldsymbol{\%})\end{array}$ & $\begin{array}{c}\text { Tempera } \\
\text { Exchange } \\
\text { Efficiency } \\
(\boldsymbol{\%})\end{array}$ & $\begin{array}{c}\text { Enthalpy } \\
\text { Exchange } \\
\text { Efficiency } \\
(\boldsymbol{\%})\end{array}$ \\
\hline 29 & 5.00 & 39.39 & 4.17 & 42.11 \\
\hline 31 & 6.67 & 50.00 & 24.32 & 46.15 \\
\hline 33 & 33.33 & 51.85 & 32.14 & 50.00 \\
\hline 35 & 40.28 & 57.81 & 42.50 & 55.93 \\
\hline 37 & 47.87 & 61.86 & 49.51 & 60.00 \\
\hline
\end{tabular}

Figure 4 shows the effect of the temperature exchange efficiency and enthalpy exchange efficiency as a function of the temperature of OA of both PP-HEXs for the second testing scenario. Based on Figure 4, the temperature exchange efficiency and enthalpy exchange efficiency of both PP-HEXs have the similar trends of directly proportional, which means that the efficiencies increase as the temperature of OA increases. Note that the temperature of RA was fixed, and the temperature of OA is varying, therefore it could be also understood that the larger the difference of the temperature between OA and RA, the higher the temperature exchange efficiency and enthalpy exchange efficiency. Hence, the result of temperature exchange efficiency and enthalpy exchange efficiency tally 
with the first testing scenario that the larger the difference of temperature between OA and RA, the better the temperature exchange efficiency and enthalpy exchange efficiency. On top of that, Figure 4 shows that the enthalpy exchange efficiency is always greater than the temperature exchange efficiency.

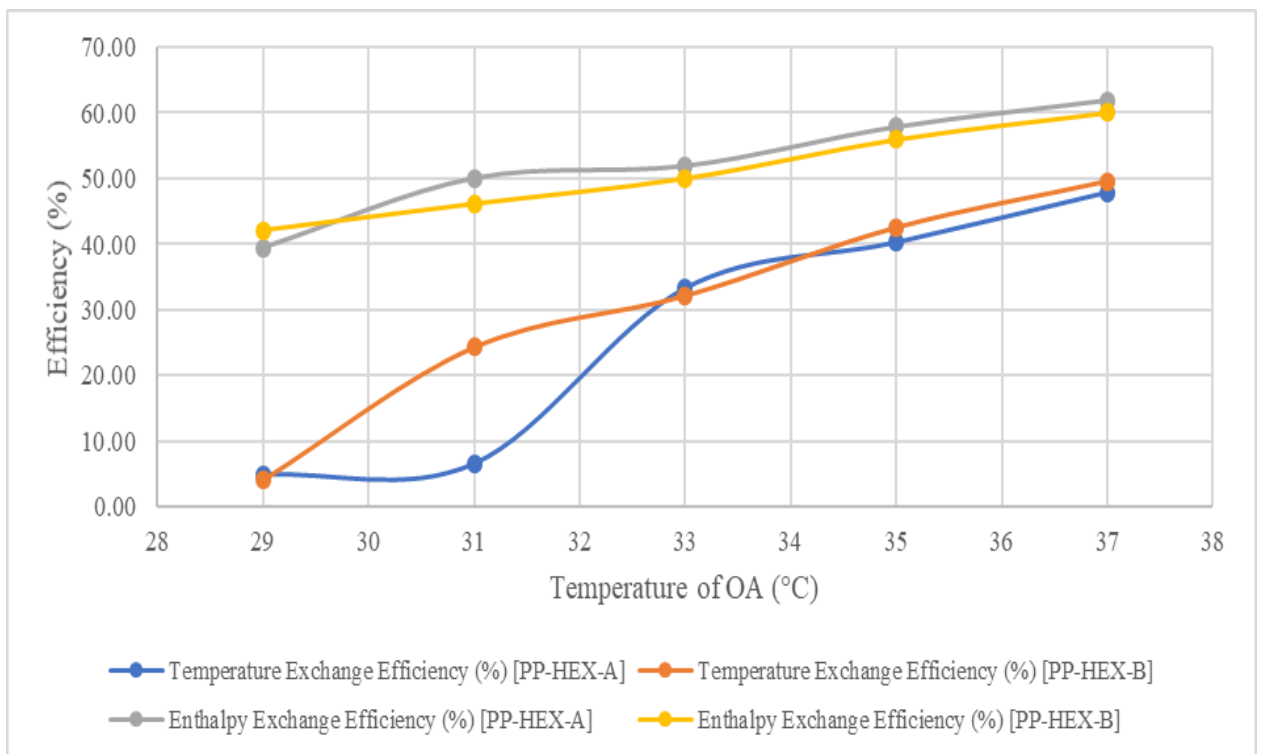

Fig. 4. Efficiency vs Temperature of RA.

\subsection{Third Testing Scenario}

The raw data, enthalpy, temperature exchange efficiency and enthalpy exchange efficiency of the third testing scenario are tabulated as shown in Tables 7, 8 and 9 respectively.

Table 7. Raw data of third testing scenario.

\begin{tabular}{|c|c|c|c|c|c|c|c|c|c|c|c|}
\hline \multicolumn{4}{|c|}{ PP-HEX-A } & \multicolumn{6}{c|}{ PP-HEX-B } \\
\hline \multicolumn{2}{|c|}{$\begin{array}{c}\text { Temperature } \\
\left({ }^{\circ} \mathbf{C}\right)\end{array}$} & \multicolumn{3}{c|}{$\begin{array}{c}\text { Relative } \\
\text { Humidity }(\%)\end{array}$} & \multicolumn{3}{c|}{$\begin{array}{c}\text { Temperature } \\
\left({ }^{\circ} \text { C) }\right.\end{array}$} & \multicolumn{3}{c|}{$\begin{array}{c}\text { Relative } \\
\text { Humidity (\%) }\end{array}$} \\
\hline RA & SA & OA & RA & SA & OA & RA & SA & OA & RA & SA & OA \\
\hline 23 & 29.5 & 35.2 & 66.9 & 46 & 44.2 & 23.4 & 30.1 & 34.9 & 62 & 49 & 44.8 \\
\hline 25 & 30.4 & 34.8 & 66.8 & 51.1 & 46 & 25.1 & 31.3 & 35.1 & 63.1 & 49.3 & 45.2 \\
\hline 27 & 31.8 & 35.1 & 67 & 54.1 & 45.8 & 26.7 & 32.1 & 35 & 61.8 & 51.7 & 45.6 \\
\hline 29 & 32.8 & 35 & 67.3 & 52.5 & 44.9 & 28.9 & 33.3 & 35.2 & 61.2 & 50.7 & 46 \\
\hline
\end{tabular}

Table 8. Enthalpy of the air under different conditions.

\begin{tabular}{|c|c|c|c|c|c|c|}
\hline \multirow[b]{2}{*}{$\begin{array}{c}\text { Temperature } \\
\text { of RA }\left({ }^{\circ} \mathbf{C}\right)\end{array}$} & \multicolumn{3}{|c|}{ PP-HEX-A } & \multicolumn{3}{|c|}{ PP-HEX-B } \\
\hline & $\begin{array}{c}\text { RA, } \\
\text { Enthalpy } \\
\text { (kJ/kg) }\end{array}$ & $\begin{array}{c}\text { SA, } \\
\text { Enthalpy } \\
(\mathrm{kJ} / \mathrm{kg})\end{array}$ & $\begin{array}{c}\text { OA, } \\
\text { Enthalpy } \\
\text { (kJ/kg) }\end{array}$ & $\begin{array}{c}\text { RA, } \\
\text { Enthalpy } \\
\text { (kJ/kg) }\end{array}$ & $\begin{array}{c}\text { SA, } \\
\text { Enthalpy } \\
(\mathrm{kJ} / \mathrm{kg})\end{array}$ & $\begin{array}{c}\text { OA, } \\
\text { Enthalpy } \\
\text { (kJ/kg) }\end{array}$ \\
\hline 23 & 53 & 60 & 76 & 51.9 & 63.8 & 75.6 \\
\hline 25 & 58.9 & 66.2 & 76.3 & 57.3 & 67.7 & 76.6 \\
\hline 27 & 65.5 & 73 & 77.2 & 61.5 & 72.1 & 76.7 \\
\hline 29 & 72.6 & 75.2 & 76 & 68.2 & 75.4 & 77.7 \\
\hline
\end{tabular}


Table 9. Temperature Exchange Efficiency and Enthalpy Exchange Efficiency.

\begin{tabular}{|c|c|c|c|c|}
\hline \multirow[b]{2}{*}{$\begin{array}{c}\text { Temperature } \\
\text { of RA }\left({ }^{\circ} \mathbf{C}\right)\end{array}$} & \multicolumn{2}{|c|}{ PP-HEX-A } & \multicolumn{2}{|c|}{ PP-HEX-B } \\
\hline & $\begin{array}{c}\text { Tempera } \\
\text { Exchange } \\
\text { Efficiency } \\
(\%)\end{array}$ & $\begin{array}{c}\text { Enthalpy } \\
\text { Exchange } \\
\text { Efficiency } \\
(\%)\end{array}$ & $\begin{array}{c}\text { Tempera } \\
\text { Exchange } \\
\text { Efficiency } \\
(\%)\end{array}$ & $\begin{array}{c}\text { Enthalpy } \\
\text { Exchange } \\
\text { Efficiency } \\
(\%)\end{array}$ \\
\hline 23 & 46.72 & 69.57 & 41.74 & 49.79 \\
\hline 25 & 44.90 & 58.05 & 38.00 & 46.11 \\
\hline 27 & 40.74 & 35.90 & 34.94 & 30.26 \\
\hline 29 & 36.67 & 23.53 & 30.16 & 24.21 \\
\hline
\end{tabular}

Figure 5 shows the effect of the temperature exchange efficiency and enthalpy exchange efficiency as a function of the temperature of RA of both PP-HEXs for the third testing scenario. Third testing scenario has the same testing procedure as the first testing scenario. However, there will be a difference in voltage supply for the third testing scenario, the voltage supply in the third testing scenario will be set at $120 \mathrm{~V}$. Thus, both testing scenarios should have the similar trend of experimental results theoretically. Based on Figure 5, the temperature exchange efficiency and enthalpy exchange efficiency have the similar trends of inversely proportional, which means that the efficiencies drop as the temperature of RA increases. Note that the temperature of OA was fixed, and the temperature of RA is varying, therefore it could be also understood that the smaller the difference of the temperature between the OA and RA, the lower the temperature exchange efficiency and enthalpy exchange efficiency. Hence, it shows that both testing scenarios have the similar trend of the experimental results and the results are theoretically tally.

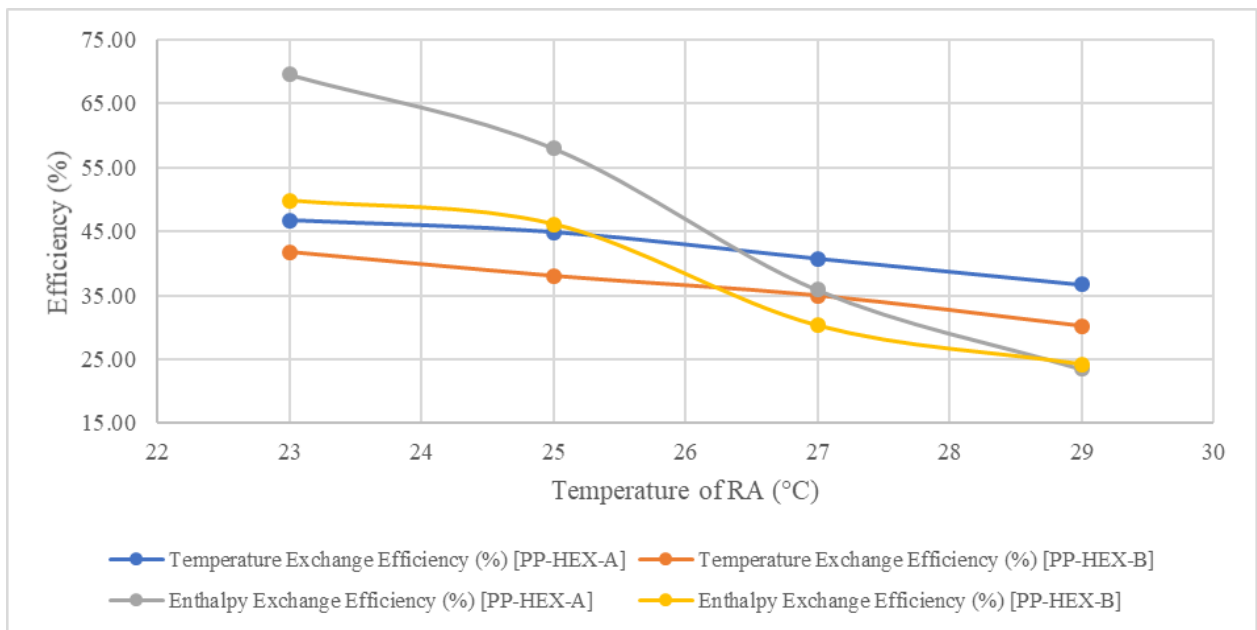

Fig. 5. Efficiency vs Temperature of RA.

\subsection{Fourth Testing Scenario}

The raw data, enthalpy, temperature exchange efficiency and enthalpy exchange efficiency of the fourth testing scenario of both PP-HEXs are tabulated as shown in Tables 10, 11 and 12 respectively. 
Table 10. Raw data of fourth testing scenario.

\begin{tabular}{|c|c|c|c|c|c|c|c|c|c|c|c|}
\hline \multicolumn{4}{|c|}{ PP-HEX-A } & \multicolumn{6}{c|}{ PP-HEX-B } \\
\hline \multicolumn{2}{|c|}{$\begin{array}{c}\text { Temperature } \\
\left({ }^{\circ} \mathbf{C}\right)\end{array}$} & \multicolumn{3}{c|}{$\begin{array}{c}\text { Relative } \\
\text { Humidity }(\%)\end{array}$} & \multicolumn{3}{c|}{ Temperature } & \multicolumn{3}{c|}{$\begin{array}{c}\text { Relative } \\
\text { Humidity (\%) }\end{array}$} \\
\hline RA & SA & OA & RA & SA & OA & RA & SA & OA & RA & SA & OA \\
\hline 27.1 & 29.4 & 29.5 & 65.5 & 58 & 58.6 & 27 & 28.9 & 29 & 60.6 & 56.8 & 57.8 \\
\hline 27 & 30.7 & 31.1 & 63.8 & 49 & 48.5 & 26.8 & 29.8 & 31.1 & 57.3 & 52 & 50.6 \\
\hline 26.9 & 30.3 & 33 & 63.5 & 50.6 & 43.3 & 27.1 & 30.8 & 33.1 & 56.1 & 48.2 & 43.3 \\
\hline 27.1 & 31.1 & 34.9 & 61.1 & 46.7 & 39.9 & 26.9 & 31.6 & 34.6 & 55.8 & 43.4 & 38 \\
\hline
\end{tabular}

Table 11. Enthalpy of the air under different conditions.

\begin{tabular}{|c|c|c|c|c|c|c|}
\hline \multirow[b]{2}{*}{$\begin{array}{c}\text { Temperature } \\
\text { of OA }\left({ }^{\circ} \mathrm{C}\right)\end{array}$} & \multicolumn{3}{|c|}{ PP-HEX-A } & \multicolumn{3}{|c|}{ PP-HEX-B } \\
\hline & $\begin{array}{c}\text { RA, } \\
\text { Enthalpy } \\
(\mathbf{k J} / \mathbf{k g})\end{array}$ & $\begin{array}{c}\text { SA, } \\
\text { Enthalpy } \\
(\mathbf{k J} / \mathbf{k g})\end{array}$ & $\begin{array}{c}\text { OA, } \\
\text { Enthalpy } \\
(\mathbf{k J} / \mathbf{k g})\end{array}$ & $\begin{array}{c}\text { RA, } \\
\text { Enthalpy } \\
(\mathbf{k J} / \mathbf{k g})\end{array}$ & $\begin{array}{c}\text { SA, } \\
\text { Enthalpy } \\
(\mathbf{k J} / \mathbf{k g})\end{array}$ & $\begin{array}{c}\text { OA, } \\
\text { Enthalpy } \\
(\mathbf{k J} / \mathbf{k g})\end{array}$ \\
\hline 29 & 64.9 & 67.8 & 68.5 & 61.7 & 65.4 & 66.3 \\
\hline 31 & 63 & 65.6 & 66.5 & 59.2 & 65 & 68 \\
\hline 33 & 63.1 & 65.5 & 68.2 & 59.4 & 65.3 & 68.5 \\
\hline 35 & 62.3 & 65.1 & 71 & 58.6 & 64.1 & 68.4 \\
\hline
\end{tabular}

Table 12. Temperature Exchange Efficiency and Enthalpy Exchange Efficiency.

\begin{tabular}{|c|c|c|c|c|}
\hline \multirow{2}{*}{$\begin{array}{c}\text { Temperature } \\
\text { of OA }\left({ }^{\circ} \mathbf{C}\right)\end{array}$} & \multicolumn{2}{|c|}{ PP-HEX-A } & \multicolumn{2}{c|}{ PP-HEX-B } \\
\cline { 2 - 5 } & $\begin{array}{c}\text { Tempera } \\
\text { Exchange } \\
\text { Efficiency } \\
(\boldsymbol{\%})\end{array}$ & $\begin{array}{c}\text { Enthalpy } \\
\text { Exchange } \\
\text { Efficiency } \\
(\boldsymbol{\%})\end{array}$ & $\begin{array}{c}\text { Tempera } \\
\text { Exchange } \\
\text { Efficiency } \\
(\boldsymbol{\%})\end{array}$ & $\begin{array}{c}\text { Enthalpy } \\
\text { Exchange } \\
\text { Efficiency } \\
(\boldsymbol{\%})\end{array}$ \\
\hline 29 & 4.17 & 19.44 & 5 & 19.57 \\
\hline 31 & 9.76 & 25.71 & 30.23 & 34.09 \\
\hline 33 & 44.26 & 52.94 & 38.33 & 35.16 \\
\hline 35 & 48.72 & 67.82 & 38.96 & 43.88 \\
\hline
\end{tabular}

Figure 6 shows the effect of the temperature exchange efficiency and enthalpy exchange efficiency as a function of the temperature of OA of both PP-HEXs for the fourth testing scenario. Fourth testing scenario has the same testing procedure as the second testing scenario but there will be a difference in voltage supply for the fourth testing scenario, the voltage supply in the fourth testing scenario will be set at $120 \mathrm{~V}$. Thus, both testing scenarios should have the similar trend of experimental results theoretically. Based on Figure 6, the temperature exchange efficiency and enthalpy exchange efficiency have the similar trends of directly proportional, which means that the efficiencies increase as the temperature of $\mathrm{OA}$ increases. Note that the temperature of RA was fixed, and the temperature of $\mathrm{OA}$ is varying, therefore it could be also understood that the larger the difference of the temperature between $\mathrm{OA}$ and RA, the higher the temperature exchange efficiency and enthalpy exchange efficiency. Hence, it shows that both testing scenarios have the similar trend of the experimental results and results are theoretically tally. However, the both efficiencies fluctuate more as compared with the experimental results of the second testing scenario. 


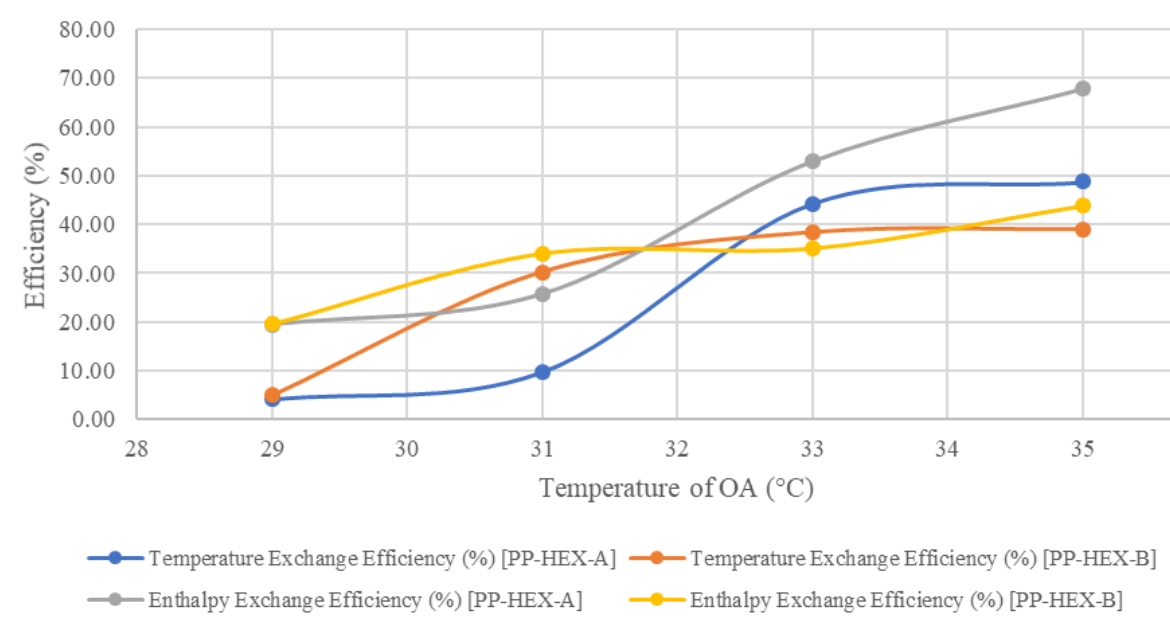

Fig. 6. Efficiency vs Temperature of RA.

All in all, PP-HEX-A has a temperature exchange efficiency and enthalpy exchange efficiency with a range of $(37.97-40.28) \%$ an $(30.77-57.81) \%$ respectively with the default voltage supply of $240 \mathrm{~V}$ and setup conditions (according to ISO Standard) of RA to be $27^{\circ} \mathrm{C}$ and $\mathrm{OA}$ to be $35^{\circ} \mathrm{C}$. While PP-HEX-B has a temperature exchange efficiency and enthalpy exchange efficiency with a range of $(35.29-42.5) \%$ an $(39.6-55.93) \%$ respectively with the default voltage supply of $240 \mathrm{~V}$ and setup conditions (according to ISO Standard) of RA to be $27^{\circ} \mathrm{C}$ and $\mathrm{OA}$ to be $35^{\circ} \mathrm{C}$. With the voltage supply of $120 \mathrm{~V}$ and ISO Standard setup conditions, PP-HEX-A has a temperature exchange efficiency and enthalpy exchange efficiency of $(40.74-48.72) \%$ and $(35.9-67.82) \%$ respectively, while PP-HEX-B has a temperature exchange efficiency and enthalpy exchange efficiency of $(34.94-38.96) \%$ and $(30.26-43.88) \%$ respectively.

Moreover, all these testing scenarios prove that the larger the difference between the temperature of RA and OA, the better the efficiencies. However, the temperature exchange efficiency has minor changes or having a very small gradient of graph in first and third testing scenarios. Note that first and third testing scenarios are having the temperature of $\mathrm{OA}$ to be fixed and varying the temperature of RA. According to a study, there will be a minor effect on the temperature exchange efficiency by having the temperature of OA to be fixed and varying the temperature of RA [18]. This study validated with the results of first and third testing scenarios. Hence, the main parameter that affects the temperature exchange efficiency will be the temperature of OA. In another word, it could be understood that controlling the temperature of RA does not contribute a significant effect on the temperature exchange efficiency, even though this experiment proved that the larger the difference in between the temperature of RA and OA, the better the efficiencies. However, controlling the temperature of $\mathrm{OA}$ would give a tremendous effect on the temperature exchange efficiency.

Furthermore, the experimental results for the efficiencies seem to fluctuate. This is because the testing was conducted in a laboratory with features of controlling the temperature which is located on the rooftop of the building and it is partially open air. The experiment was completed within two weeks and some of the testing scenarios were conducted during sunny and rainy days. Therefore, the humidity will be affected for all the testing scenarios. On top of that, the aluminum ducting which was used to direct RA to the VHR was exposed out of the laboratory. So, there will be heat radiation affecting the temperature of RA and causing a minor influence towards the results. Hence, these factors 
had led to the fluctuation of the experimental results. According to finding, the results of temperature exchange efficiency and enthalpy exchange efficiency will be influenced by the temperature of RA [19].

\section{Conclusion}

The experimental results of all testing scenarios show minor fluctuation. However, the experimental results are supported with some of the findings. There are several important parameters to be considered in the future optimization study to minimize the errors in results. The temperature exchange efficiency shows positive results in all testing scenarios, as they provide similar trends of graph that the larger the temperature difference between $\mathrm{OA}$ and RA, the better the temperature exchange efficiency. In addition to this point, the difference in temperature of OA provides a significant effect towards the temperature exchange efficiency but the difference in temperature of RA does not. Hence, it can be concluded that the performance and efficiencies of PP-HEX is strongly dependent on the ambient climatic conditions. Based on what has been learned from literature review, there are physical and performance parameters required to be well considered for the VHR regardless of conducting experimental testing or real-life application. The other important parameters are structure of PP-HEX, size of the fan used in VHR, configuration of airflow, airflow velocity etc. Besides, the operation parameters such as temperature, humidity and air velocity of the VHR must be well considered throughout the future optimization study as well.

In a nutshell, this research tackled the objective of studying the performance of the first PP-HEX under different return and outdoor air temperatures as well as their effect on both enthalpy and temperature exchanger efficiency. And this research is meant to contribute to the numerical analysis with the experimental results. The numerical analysis is meant to reduce the experimental work and reduce the experimental cost in a way, also it helps engineers or designers to improvise the design or prototype with ease and reduces the time needed for experimental testing. Therefore, this research can be considered as contributing for the economical improvisation for future development of PP-HEX in a way.

Hereby, I would like to express my greatest gratitude and appreciation towards Daikin Research and Development Sdn. Bhd. for providing this golden opportunity to be a part of this research, and to gain first-hand experience and knowledge from the various lab experiments and testing. Throughout the journey, they guided thoroughly with their area of expertise and provided necessary equipment and support which allows this research to be successfully done. Lastly, I look forward for more opportunities in the future to be able to collaborate with Daikin Research and Development Sdn. Bhd.

\section{References}

1. I. Turiel, Indoor air quality and human health. Stanford University Press (1985)

2. Y. Al horr, M. Arif, M. Katafygiotou, A. Mazroei, A. Kaushik, E. Elsarrag, Int. J. Sustainable Built Environ., 5, 1, 1-11 (2016)

3. J. Bermejo-Busto, C. Martín-Gómez, A. Zuazua-Ros, E. Baquero, R. Miranda, Energy Build., 134, 25-36 (2017)

4. A. M. Papadopoulos, Energy Build., 37, 1, 77-86 (2005)

5. P. Kumar, C. Martani, L. Morawska, L. Norford, R. Choudhary, M. Bell, M. Leach, Energy Build., 111, 145-153 (2016).

6. A. Mardiana, S. B. Riffat, Renewable Sustainable Energy Rev., 28, 174-190 (2013).

7. J. Kragh, J. Rose, T. R. Nielsen, S. Svendsen, Energy Build., 39, 11, 1151-1158 (2007) 
8. Y. El Fouih, P. Stabat, P. Rivière, P. Hoang and V. Archambault, Energy Build., 54, 29-39 (2012)

9. $\quad$ S.-M. Kim, J.-H. Lee, S. Kim, H. J. Moon, J. Cho, Energy Build., 46, 3-13 (2012).

10. Y. Wang, F.-Y. Zhao, J. Kuckelkorn, D. Liu, L.-D. Liu, X.-C. Pan, Energy, 64, 9911001 (2014)

11. Z. Liu, W. Li, Y. Chen, Y. Luo, L. Zhang, Appl. Therm. Eng., 148, 544-556 (2019)

12. S. Sabek, F. Tiss, R. Chouikh, A. Guizani, Appl. Therm. Eng., 130, 211-220 (2018)

13. C. Beattie, P. Fazio, R. Zmeureanu, J. Rao, Appl. Therm. Eng., 129, 1281-1291 (2018)

14. J. Min, M. Su, Appl. Therm. Eng., 31, 17-18, 4036-4043 (2011).

15. American Society of Heating, 2005 ASHRAE handbook: fundamentals., ASHRAE, (2005)

16. H. Han, Y.-B. Choo, Y.I. Kwon, Proceedings of CLIMA 2007 WellBeing Indoors, (2007)

17. G. Gan, S. B. Riffat, Build. Serv. Eng. Res. Technol., 18, 2, 67-75 (1997)

18. W. Yaïci, M. Ghorab E. Entchev, Appl. Therm. Eng., 51, 1-2, 770-780 (2013)

19. Y. H. Yau, Int. J. Refrig., 30, 7, 1143-1152 (2007) 